\title{
Influence of Process Parameters on the Surface Roughness during turning operation of High Strength Steel
}

\author{
Adel Taha Mohamed Abbas ${ }^{1}$ \\ ${ }^{1}$ Department of Mechanical Engineering, College of Engineering, King Saud University, Saudi Arabia \\ Correspondence: Adel Taha Mohamed Abbas, Department of Mechanical Engineering, College of Engineering, \\ King Saud University, Saudi Arabia. E-mail: atabbas1954@yahoo.com
}

\author{
Received: December 17, 2015 Accepted: February 15, $2016 \quad$ Online Published: February 23, 2016 \\ doi:10.5539/jmsr.v5n2p100 URL: http://dx.doi.org/10.5539/jmsr.v5n2p100
}

\begin{abstract}
High strength steels are used in many high-end applications. Due to the high cost of raw material, manufacturing engineers should be very careful during their machining process. Surface finish is the critical factor in the turning process of combustion chambers of gun barrels. It should conform to the required accuracy values. This paper analyzes the impact and parameters of the process have on the roughness of the surface. The impact is analyzed during turning operations of high strength steel material. The parameters considered include feed rate, depth of cut and cutting speed. The test plan was implemented through 125 test specimens. The latters were divided into 25 groups. Each five groups were subjected to one common machining speed. Each group was machined using five levels of cutting depth. Each depth was processed using feed rate having five levels. Tessa was used for the examination of the roughness of surface. The experimental findings were compared to the requirement of the surface finish on the basis of the design drawing of gun barrel. The combination of the process variables showed excellent agreement with the design drawing of gun barrels.
\end{abstract}

Keywords: Parameters, process, feeds, cutting-depth, surface-finish, wet-machining, dry-machining, Tessa, gun-barrels

\section{Introduction}

Many uses exist for high strength steel materials processed via precision turning in high pressure vessel type products. Examples of the turned high pressure products include; gun barrels, food sterilization equipment, high-precision sintering dies, hypersonic (up to Mach 16) wind tunnels, water jet cutting nozzles and turbine casings for efficient power generation. This work documents a series of exploratory experiments with cutting parameters for a class of high-grade high strength steel (tempred, with hardness HV 400-420), with the aim of identifying the optimum conditions for best surface finish and productivity.

Example relevant work in the literature include the work of Carou, Rubio, Lauro, and Davim (2014), where an experimental investigation was conducted on intermittent turning of UNS M11917 magnesium alloy, analyzing different machining conditions. The variables included speed of cutting, depth of cut, and speed rate. It was supplemented by dry machining system and Minimum Quantity Lubrication. To evaluate intermittent turning process, continuous bars and slotted bars were used. The evaluation of surface roughness was carried out using a Hommel Tester T1000 profilometer. This process is evaluated taking as response variable the surface roughness. Full factorial experimental designs are used and their results are analyzed by examining the differences in the mean scores of the scores through variance analysis. Main results of the statistical analysis include the feed rate determination as the main significant factor for all the tests, explaining the most part of the variability analyzed. By contrast, cutting speed and type of interruption were not found to be significant sources of variability when analyzed in isolation. Moreover, more dispersion of surface roughness values, in terms of Ra, was identified when machining at low feed rates which can be difficult its prediction. In addition, when analyzing depth of cut, this factor and its association with feed rate are also found to be significant sources of variability for Ra. Finally, the impact of the environment is also analyzed in the context of machining process, finding that the use of the MQL system may result in slightly worse surface roughness denoted by Ra at the higher tested rates of feed.

C. J. Rao, D. N. Rao, and Srihari (2013) discussed in their research reports the significance of speed factor, rate of feed, and cutting depth on the roughness of the surface and cutting force while working with tool made of ceramic with an Al2O3+TiC matrix (KY1615) and the work material of AISI 1050 steel (hardness of 484 HV). 
Experiments were conducted using Johnford TC35 Industrial type of CNC lathe. Taguchi method (L27 design with 3 levels and 3 factors) was used for the experiments. Analysis of variance with adjusted approach has been adopted. According to the findings, feed rate has significant association with cutting force. It also has significant association with surface roughness. Depth of cut was found to be not related with cutting force. Davim (2001) describes the relationship between the conditions of cutting and the surface finish that can be achieved by turning. An experiment plan, derived from the methods of Taguchi, was developed and implemented with cutting conditions on controlled machining prefixed in work pieces. Afterwards, the roughness was examined on work pieces through the use of two types of Profolometer. The aim was to find the relationship between cutting velocity, feed, cutting velocity, and cutting depth, where R represents the parameters that evaluate roughness, and R" adheres to the international norms. The correlations were calculated by running the test of multiple linear regressions. The best fit model for explaining the variability is the non-linear quadratic model. It explains the variability in surface roughness with dominant predictability by feed rate and additional predictability by cutting depth and rate of feed. It also explains the quadratic impact of second order for feed rate and association impact between cutting depth and speed. The recommended cutting forces and surface roughness models are adequate for mapping within the framework of the parameters of cutting considered. It is important to note however, that Taguchi methods relying on orthogonal arrays can often miss nonlinear interactions between the observed variables when such interactions exist.

Lalwani, Mehta, and Jain (2008) endeavored to evaluate the impact of cutting parameters including speed of cutting, rate of feed, and cutting depth. The cutting forces serve as the dependent variable. The impact is also evaluated on the roughness of surface in MDN250 steel's finish hard turning. The edge preparations included honed edges and chamfered edges as shown in Figure 2. The findings indicate no significant relationship of cutting speed with cutting forces and surface roughness from 55 meter per minute to 93 meter per minute. A linear model explains 89 percent variability in the feed force. In case of the rate of feed, the indicator explains 6.61 percent of the variability in feed force. For the dependent variable cutting force, independent variables cutting depth and feed rate explain $41.63 \%$ and $52.60 \%$ variability. Diniz and Micaroni (2002) study the avoiding of the vicinity of cutting fluids. The fluids are inspected in courses of action of machining. It was investigated by diverse researchers connected with the modern part, for the reasons of human wellbeing and ecological issues came about because of the fluids. Be that as it may, fluids have their significance in giving a more noteworthy existence of hardware for diverse operations connected with machining. It is apparent in the operation of turning of steel that makes utilization of the additions that are covered carbide. The study expects to recognize the states of cutting that are suitable dry cutting compatible, i.e., circumstances that characterize life of the apparatus during the time spent dry cutting, such that it is close to the cutting including liquid, with no harm to the work piece roughness of the surface and with no increment in the force of cutting used at the methodology level. For the achievement of these points distinctive investigations of get done with turning were performed, with the variations of feed, speed of cutting, and range of hardware nose, without using and with using the cutting liquid. The discoveries prescribed removal of the liquid from the methodology of turning of completion, with no damage to cutting time and apparatus life and experiencing improvement in force expended and roughness of surface, it is vital to upgrade the range of hardware nose and rate of feed and reduce speed of cutting.

Oktem, Erzurumlu, and Kurtaran (2005) endeavored to present a method for identifying the best conditions of cutting that result in the least roughness of surface in the mold surfaces' milling operation by making use of developed genetic algorithm (GA) and Response Surface Model (RSM). Response Surface Methodology develops an effective model of analysis in relation to parameters of cutting such as radial and axial depth of cut, feed, machining tolerance, and cutting speed. These tests prove useful for the collection of values of the roughness of surface. A fourth order RSM model is presented that utilizes test measurements in the form cavity. Response surface model is integrated with the genetic algorithm for optimizing the conditions of cutting for required surface roughness. The genetic algorithm minimizes the value of the roughness of the surface from $0.412 \mathrm{~m}$ to $0.375 \mathrm{~m}$ in the mold cavity that corresponds to almost 10 percent enhancement. Best conditions of cutting resulting from genetic algorithm are conformed to the measurements of experiments. A primary limitation of response surface type of approaches (whether linear such as in Lalwani, Mehta, and Jain (2008); Diniz and Micaroni (2002)) or nonlinear such as in Oktem, Erzurumlu, and Kurtaran (2005); Durairaj and Gowri (2013); Kant and Sangwan (2014) is that the obtainable results are highly dependent on the quality and accuracy of the response surface, which can be difficult to establish without a large number of experimental samples. Oftentimes however, a response surface is a "necessary evil" in order to allow use of advanced stochastic optimization approaches such as genetic algorithm, because otherwise the number of sample experiments needed becomes unreasonably large (several thousands). However, the quality of obtainable solutions via the genetic algorithm remains limited by the quality of the response surface. 
In studies that seek to minimize the environmental impact of the machining operations, Mahamani (2014) contributes in his study the effect of TiB2 and ZrB2 reinforcements, which are formed by in-situ chemical reaction in machining this composite. Shahrom, Yahya, and Yusoff (2013) develops an examination into wet machining and MQL (Minimum Quantity Lubricant) in the processes of milling of the work material of AISI 1060 Aluminum with the intent to identify the correlation between lubrication conditions and surface roughness. Each parameter is analyzed at four levels. The feed rate ranges are $0.25 \mathrm{~mm} / \mathrm{min}, 0.20 \mathrm{~mm} / \mathrm{min}, 0.15 \mathrm{~mm} / \mathrm{min}$, and $0.05 \mathrm{~mm} / \mathrm{min}$. The ranges of the speed of cutting were $1200 \mathrm{~mm} / \mathrm{min}, 100 \mathrm{~mm} / \mathrm{min}, 800 \mathrm{~mm} / \mathrm{min}$, and $600 \mathrm{~mm} / \mathrm{min}$. The scopes of cutting profundity were 0.8 millimeter, 0.6 millimeter, 0.4 millimeter, and 0.2 millimeter. The harshness of the surface was figured through the utilization of surface unpleasantness analyzer. The name of the analyzer is Mitutoyo. The name of the strategy used for foreseeing the surface harshness is Taguchi. Finally, the test outcomes showed great support for the evaluated results. The discoveries demonstrated that Minimum Quantity Lubricant brought about enhanced surface complete in examination to machining that is wet. These discoveries can add to the minimization of the natural contamination and expense. Nian, Yang, and Tarng (1999) recommended optimizing of turning operations founded on the method of Taguchi with different characteristics of performance. Experimental results is given for the illustration of the effectiveness of this method. Bordin, Bruschi, and Ghiotti (2014) study that the dynamic processes and increase of the machining parameters optimizing the information which is essential for production got significantly harder.

Bordin, Bruschi, and Ghiotti (2014) found that CoCrMo alloy is a biocompatible material and high-wear resistant currently used in producing medical implants, which are forged or cast. They are subsequently processed to final dimensions. The study analyzed the impact of process parameters on CoCrMo alloy bars' surface integrity under dry conditions subjected to longitudinal turning. The surface integrity was investigated in terms of surface finish, sub-surface microstructure refinement and micro-hardness, residual stresses. The presented results show that under certain conditions the part surface integrity is not altered by the dry conditions. Hessainiat et al. (2013) this study is related to the presentation of a model of the roughness of surface in the case of hard turning. It makes use of the methodology of response surface. The key variables used in the study are the parameters of cutting. These include feed rate, speed of cutting, tool vibration, and cutting depth in radial and in the directions of the main force of cutting. The material of tested machining is the hardened steel ( $42 \mathrm{CrMo} 4)$ by cutting tool of mixed ceramic (Al2O3 / TiC) for various circumstances. The model is best fit for the estimation of the roughness of surface RT and Ra by making use of machining steels with test data. The overall influence of tool vibration and cutting parameters on the roughness of surface was examined while implementing the statistical test of group differences. Davoodi \& Tazehkandi (2014) in this research, the impacts of the speed of cutting and unreformed chip thickness on feed force and cutting components and tool tip temperature were experimentally investigated in order to remove cutting fluid. High $\mathrm{Mg}$ content (4.5\%) with AA5083-O wrought alloy was machined in dry and wet machining conditions utilizing coated carbide tool. Two-factor (cutting speed and unreformed chip thickness) and fractional experiment designs of five-level done with the statistical test of group variances were conducted. The Response Surface Methodology's quadratic modeling related to the composite desirability and the technique of response optimization was employed for the determination of optimum values of tool vibration and cutting parameters in relation to stated aims that predict the surface roughness.

Abbas (2016) presented a performance comparative analysis, involving the criteria of surface roughness (Ra, Rt and Rz) during high strength steel's turning operation, between the conventional and wiper inserts. The main parameters considered in this study were the speed of cutting (CS), the feed rate (FR), and the depth of cut (DOC). The results showed the significance of cutting depth and feed rate in the reduction of surface roughness. It was reported that the quality of the surface derived with the wiper carbide insert had significant improvement in comparison to the conventional carbide insert. The maximum improvement of 3.5 times between the wiper insert and conventional insert was achieved at a surfacing speed of $75 \mathrm{~m} / \mathrm{min}$.

Based on critique of related work in the literature, the study in this work focusses on the three cutting parameters of highest significance: cutting speed, feed rate and depth of cut. Environmental impact is an objective of significant importance, however since the experiments considered employ dry machining (made possible through adoption of advanced tool materials), the environmental impact of the turning process, which can be highly dependent on the quantity of cutting fluids used, becomes insensitive to the three studied cutting parameters, and hence the primary objective to consider is that of surface quality, with Ra roughness as its measure. Rather than employ fractional factorial or response surface methodology, an investment was made in more thorough five-level full factorial experimentation setup. This is perceived to provide a better wholistic mapping of the adjustable ranges of the cutting parameters. The next section of the paper presents details of the conducted experiments, which is then followed by an analysis of the obtained results. 


\section{Materials and Methods}

Chemical compositions of the high strength steel material studied is shown in Table-1. Heat treatment for material was austenitized at $900 \mathrm{C}$ for $5 \mathrm{hr}$., air cooled, heated at $880 \mathrm{C}$ for $5 \mathrm{hr}$., quenched in oil, tempered at 590-600 C for $8 \mathrm{hr}$. then air cooled. Hardness was HV 400-420.The test specimens with initial diameter is 50 $\mathrm{mm}$ and the length is $120 \mathrm{~mm} .30 \mathrm{~mm}$ will be used for the chuck clamping and $10 \mathrm{~mm}$ for clearance grooving and $60 \mathrm{~mm}$ will be used for applying the test experiment. A standard conical center was created for supporting the center of the tail stock.

Table 1. Chemical composition of the high strength steel material

\begin{tabular}{llllllllll}
\hline Element & $\mathrm{C}$ & $\mathrm{Si}$ & $\mathrm{Mn}$ & $\mathrm{Ni}$ & $\mathrm{Cr}$ & $\mathrm{Mo}$ & $\mathrm{V}$ & $\mathrm{S}$ & $\mathrm{P}$ \\
\hline Min. \% & 0.32 & & 0.55 & 2.5 & 0.9 & 0.45 & 0.09 & & \\
Max. \% & 0.36 & $\leq 0.25$ & 0.65 & 3.2 & 1.1 & 0.55 & 0.12 & $\leq 0.004$ & $\leq 0.008$ \\
\hline
\end{tabular}

The Surface Roughness and tolerances are Critical parameters further evaluation in the control quality of the production process of many pieces machined. These pieces consumers increasingly demand better surface finish and closer margins of tolerance, but with lower costs, which encourages research into the processes that cause said surface quality to determine the influence of the variables involved in the finish. The surface quality of a piece is measured with integrity surface dad that part of the surface topology, takes into account the mechanical and metallurgical properties, important in fatigue, corrosion resistance or service life of the part. The surface topology is identified by its surface texture, which are measured various amounts related to deviations produced in part with respect to the nominal surface. The surface roughness is the most representative parameter to describe the surface texture due to its influence directly in drag, fatigue, electronic and thermal resistance mica. This is why the importance of using models allowing help determine the optimum conditions more machining for obtaining a good finish superficial. The aim of the machining operations on the phase finish is to obtain the required surface quality and dimensional tolerance, with a wear Minimum tool and with the minimum possible time, which impacts the end to reduce costs manufacture.

EMCO Concept Turn 45 CNC lathe equipped with Sinumeric 840-D (similar to the one used in Durairaj and Gowri, 2013) was used to conduct experimental work. The uncoated tungsten carbide insert was clamped with the tool holder to carry out this work. The specification for insert and tool holder are SVJCL2020K16 and VCMT160404. The clearance angle, cutting edge angle and nose radius are maintained by $7^{\circ}, 75^{\circ}$ and $0.4 \mathrm{~mm}$ respectively, similar to setups in (Carou, Rubio, Lauro, \& Davim, 2014; Lalwani, Mehta, \& Jain, 2008). The surface roughness was measured and reported for a length of $50 \mathrm{~mm}$. and evaluated using surface roughness tester Tessa (Durairaj \& Gowri, 2013). All cutting parameters were controlled via CNC part program.

To ensure a richly dense exploration of the adjustable space of the cutting parameters, a five-level full factorial design of experiments (total of 125 test conditions for three study parameters) was adopted. Listing of the factor levels for the study parameters are provided in Table 2. Equal spacing density of samples was used, except for the lowest levels of feed rate (which were perceived to be a sensitive range), where the sampling density was doubled. For efficient experimentation, the 125 samples were divided into 5 primary groups (same cutting speed for each primary group), with each primary group divined into 5 sub-groups (each having the same depth of cut). Full listing of all samples and the resulting measured surface roughness is provided in the Appendix.

Table 2. Factor Levels of the Full Factorial Experimentation

\begin{tabular}{llll}
\hline Factor/Factor-Level & Cutting Speed $(\mathrm{m} / \mathrm{min})$ & Depth of Cut $(\mathrm{mm})$ & Feed Rate $(\mathrm{mm} / \mathrm{rev})$ \\
\hline 1 & 75 & 0.1 & 0.025 \\
2 & 100 & 0.2 & 0.050 \\
3 & 125 & 0.3 & 0.100 \\
4 & 150 & 0.4 & 0.150 \\
5 & 175 & 0.5 & 0.200 \\
\hline
\end{tabular}




\section{Results and Discussion}

Full listing of the experimental samples and the resulting observed surface roughness are provided in the Appendix. Plots of the results are shown in Figure 1a-1e. Before analyzing the observed trends, some statistical tests were conducted to ensure integrity of the results. The statistical analysis used the software SPSS, with Ra surface roughness as the dependent variable versus group number, and the three cutting parameters as independent variables. The tests conducted were multi-variate regression, one-way ANOVA and Post-Hoc (for feed rates), with results of the statistical tests listed in Table 3-5. As expected, SPSS excluded the group number from being a predictor, which indicates that machine setup and stock changes were correctly conducted in a way that has no significant observable effect on the results, and that the studied cutting parameters are indeed the main explanatory variables.

Table 3. Results of Multi-Variate Regression Test

Model Summary
\begin{tabular}{|l|c|r|r|r|}
\hline Model & R & R Square & $\begin{array}{c}\text { Adjusted R } \\
\text { Square }\end{array}$ & $\begin{array}{c}\text { Std. Error of } \\
\text { the Estimate }\end{array}$ \\
\hline 1 & $.936^{\mathrm{a}}$ & .875 & .872 & .318885 \\
\hline
\end{tabular}

a. Predictors: (Constant), Feed, Depth_of_Cut, Speed

Table 4. ANOVA test

ANOVA

Surface_Finish

\begin{tabular}{|l|r|r|r|r|r|}
\hline & \multicolumn{1}{|c|}{$\begin{array}{c}\text { Sum of } \\
\text { Squares }\end{array}$} & \multicolumn{1}{c|}{$\mathrm{df}$} & Mean Square & \multicolumn{1}{c|}{$\mathrm{F}$} & Sig. \\
\hline Between Groups & 90.510 & 4 & 22.628 & 333.010 & .000 \\
Within Groups & 8.154 & 120 & .068 & & \\
Total & 98.664 & 124 & & & \\
\hline
\end{tabular}

Table 5. Results of Post Hoc Tests

Post Hoc Tests

Dependent Variable: Surface_Finish

Tukey HSD

\begin{tabular}{|c|c|c|c|c|c|c|}
\hline \multirow[b]{2}{*}{ (l) Feed } & \multirow[b]{2}{*}{ (J) Feed } & \multirow{2}{*}{$\begin{array}{c}\text { Mean } \\
\text { Difference (l- } \\
\mathrm{J})\end{array}$} & \multirow[b]{2}{*}{ Std. Error } & \multirow[b]{2}{*}{ Sig. } & \multicolumn{2}{|c|}{$95 \%$ Confidence Interval } \\
\hline & & & & & Lower Bound & Upper Bound \\
\hline \multirow[t]{4}{*}{.025} & .050 & .045680 & .073729 & .972 & -.15853 & .24989 \\
\hline & .100 & $-.508400^{\star}$ & .073729 & .000 & -.71261 & -.30419 \\
\hline & .150 & $-1.248440^{x}$ & .073729 & .000 & -1.45265 & -1.04423 \\
\hline & .200 & $-2.207280^{\star}$ & .073729 & .000 & -2.41149 & -2.00307 \\
\hline \multirow[t]{4}{*}{.050} & .025 & -.045680 & .073729 & .972 & -.24989 & .15853 \\
\hline & .100 & $-.554080^{\star}$ & .073729 & .000 & -.75829 & -.34987 \\
\hline & .150 & $-1.294120^{*}$ & .073729 & .000 & -1.49833 & -1.08991 \\
\hline & .200 & $-2.252960^{\star}$ & .073729 & .000 & -2.45717 & -2.04875 \\
\hline \multirow[t]{4}{*}{.100} & .025 & $.508400^{n}$ & .073729 & .000 & .30419 & .71261 \\
\hline & .050 & $.554080^{*}$ & .073729 & .000 & .34987 & .75829 \\
\hline & .150 & $-.740040^{\star}$ & .073729 & .000 & -.94425 & -.53583 \\
\hline & .200 & $-1.698880^{*}$ & .073729 & .000 & -1.90309 & -1.49467 \\
\hline \multirow[t]{4}{*}{.150} & .025 & $1.248440^{n}$ & .073729 & .000 & 1.04423 & 1.45265 \\
\hline & .050 & $1.294120^{\star}$ & .073729 & .000 & 1.08991 & 1.49833 \\
\hline & .100 & $.740040^{\star}$ & .073729 & .000 & .53583 & .94425 \\
\hline & .200 & $-.958840^{\star}$ & .073729 & .000 & -1.16305 & -.75463 \\
\hline \multirow[t]{4}{*}{.200} & .025 & $2.207280^{n}$ & .073729 & .000 & 2.00307 & 2.41149 \\
\hline & .050 & $2.252960^{\star}$ & .073729 & .000 & 2.04875 & 2.45717 \\
\hline & .100 & $1.698880^{\star}$ & .073729 & .000 & 1.49467 & 1.90309 \\
\hline & .150 & $.958840^{*}$ & .073729 & .000 & .75463 & 1.16305 \\
\hline
\end{tabular}

*. The mean difference is significant at the 0.05 level. 
The three considered cutting parameters combined had R-squared value of 0.875 in the multi-variate regression, which implies that the independent variables explain 87.5 percent of the variability of the dependent variable, and results of ANOVA (large F value of 333) re-affirms this. Post Hoc Tests results shown in Table 5 show that the difference in surface finish is not significant when the rate of feed increases from 0.050 to 0.100 . However, the difference becomes significant when the rate of feed increases to 0.1 and onwards.
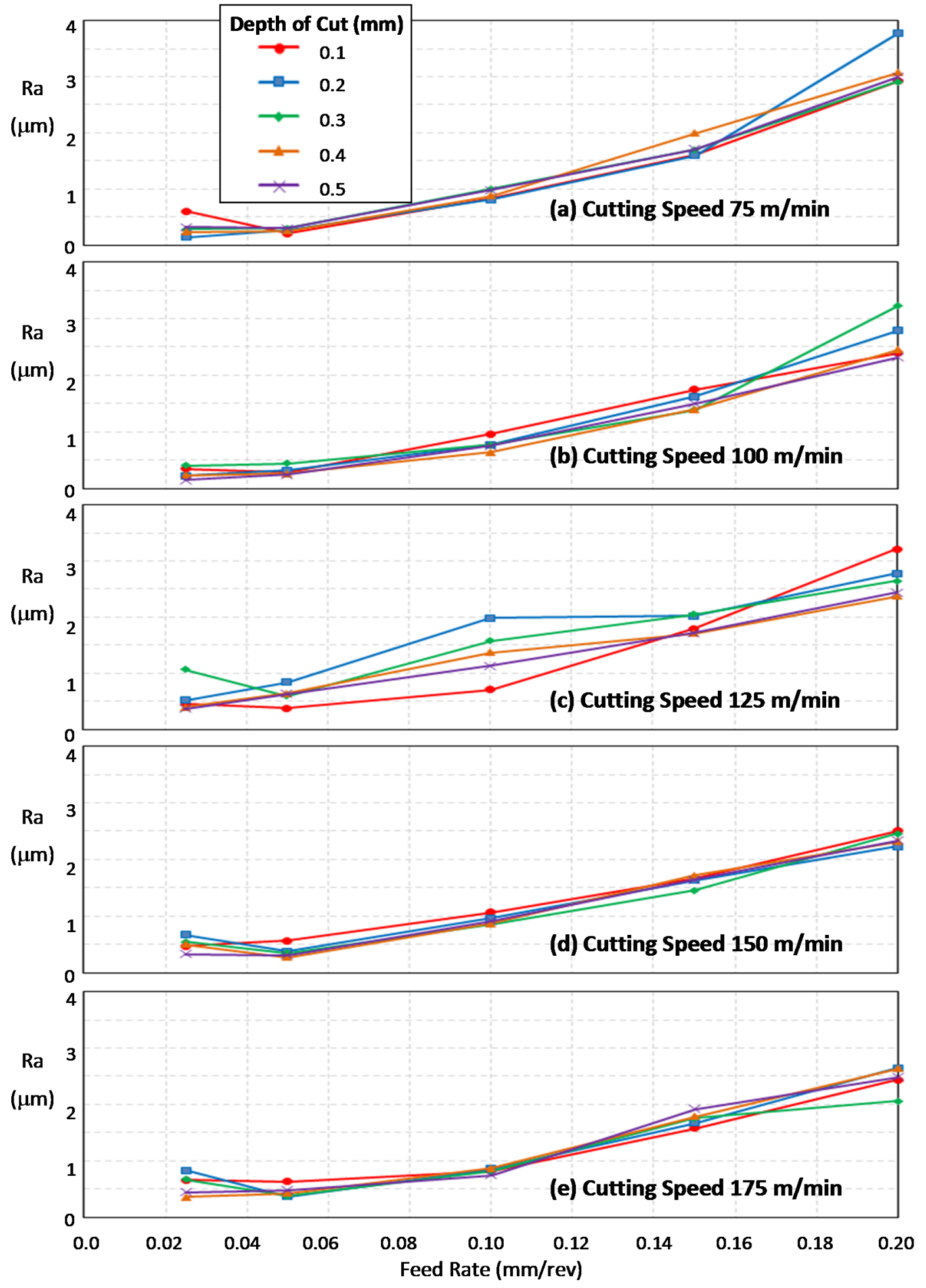

Figure 1. Experimentation results for surface roughness 
Observation of Figure 1 shows the surface roughness to exhibit its highest sensitivity relative to the feed rate. However, the optimum surface finish seems quite sensitive to finding the right combination of cutting speed, depth of cut and feed rate. While the overall trend seems to favor smaller values for all cutting parameters, there are interesting crossovers/reverse trends happening at certain combinations, which may merit further investigation into the cause of such outcome using vibration and temperature sensors (not part of the current experimental setup) in future work.

Among currently explored samples, highlight is given to three notable combinations of the cutting parameters, which are listed in Table 6. Sample \#6 has the best surface quality (minimum Ra surface roughness) among all 125 test samples, yet has small values for all three cutting parameters, which is unfavorable in terms of productivity (in terms of material removal rate). Setting sample \#6 as a baseline for normalization (Figure 2), sample \#92 has about half the surface quality (approx. twice the Ra roughness), yet eight times the material removal rate as sample \#6. Sample \#46 on the other hand, only compromises 5\% surface quality and has 3.3 times the material removal rate as sample \#6.

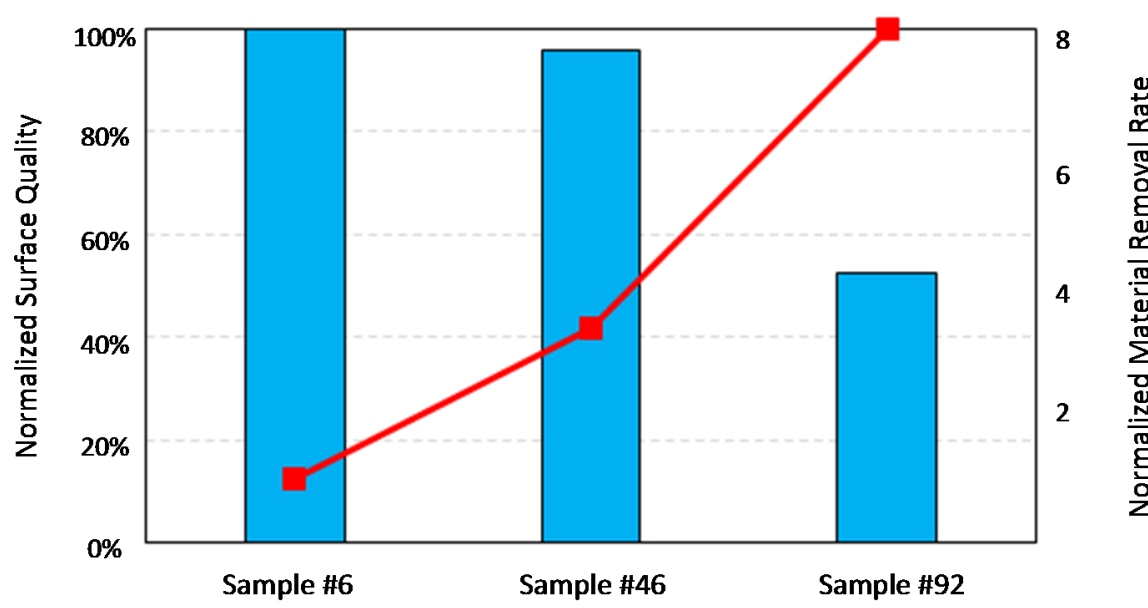

Figure 2. Normalized surface quality and material removal rate for select samples

Table 6. Sample with best obtained surface finish and notable compromises

\begin{tabular}{ccccc}
\hline Sample ID & $\mathrm{Ra}(\mu \mathrm{m})$ & Cutting Speed $(\mathrm{m} / \mathrm{min})$ & Depth of cut $(\mathrm{mm})$ & Feed Rate $(\mathrm{mm} / \mathrm{rev})$ \\
\hline 6 & 0.141 & 75 & 0.2 & 0.025 \\
46 & 0.147 & 100 & 0.5 & 0.025 \\
92 & 0.269 & 150 & 0.4 & 0.05 \\
\hline
\end{tabular}

\section{Conclusions}

An elaborate experimental study has been conducted for optimization of CNC turning operations for a high-strength steel material. The study included 5-level full factorial sampling of cutting speed, depth of cut and feed rate, with a total of 125 test samples. Feed rate was found to be the parameter with highest sensitivity, but all three parameters were statistically significant according to statistical tests. The best attained surface quality had roughness $\mathrm{Ra}$ as low as $0.141 \mu \mathrm{m}$, but other good compromises with significantly improved material removal rate were also observed. Future extensions of this work may explore avenues for further improvement in surface quality and productivity via adaptive sequential sampling approaches, as well as modeling (empirical or multi-scale numerical simulations) and validation.

\section{References}

Abbas, A.T. (2016). Comparative Assessment of Wiper and Conventional Carbide Inserts on Surface Roughness in the Turning of High Strength Steel Comparative Assessment of Wiper and Conventional Carbide Inserts on Surface Roughness in the Turning of High Strength Steel. Journal of Materials Science Research, 5(1), $32-45$. 
Bordin, A., Bruschi, S., \& Ghiotti, A. (2014). The Effect of Cutting Speed and Feed Rate on the Surface Integrity in Dry Turning of CoCrMo Alloy. Procedia CIRP, 13, 219-224. http://dx.doi.org/10.1016/j.procir. 2014.04.038

Carou, D., Rubio, E. M., Lauro, C. H., \& Davim, J. P. (2014). Experimental investigation on surface finish during intermittent turning of UNS M11917 magnesium alloy under dry and near dry machining conditions. Measurement, 56, 136-154. http://dx.doi.org/10.1016/j.measurement.2014.06.020

Davim, J. P. A. (2001). note on the determination of optimal cutting conditions for surface finish obtained in turning using design of experiments. Journal of materials processing technology, 116(2), 305-308. http://dx.doi.org/10.1016/S0924-0136(01)01063-9

Davoodi, B., \& Tazehkandi, A. H. (2014). Experimental investigation and optimization of cutting parameters in dry and wet machining of aluminum alloy 5083 in order to remove cutting fluid. Journal of Cleaner Production, 68, 234-242. http://dx.doi.org/10.1016/j.jclepro.2013.12.056

Diniz, A. E., \& Micaroni, R. (2002). Cutting conditions for finish turning process aiming: the use of dry cutting. International Journal of Machine Tools and Manufacture, 42(8), 899-904. http://dx.doi.org/10.1016/S0890 -6955(02)00028-7

Durairaj, M., \& Gowri, S. (2013). Parametric optimization for improved tool life and surface finish in micro turning using genetic algorithm. Procedia Engineering, 64, 878-887. http://dx.doi.org/10.1016/j.proeng. 2013.09.164

Hessainiat, Z., Belbah, A., Yallese, M. A., Mabrouki, T., \& Rigal, J. F. (2013). On the prediction of surface roughness in the hard turning based on cutting parameters and tool vibrations. Measurement, 46(5), 1671-1681. http://dx.doi.org/10.1016/j.measurement.2012.12.016

Kant, G., \& Sangwan, K. S. (2014). Prediction and optimization of machining parameters for minimizing power consumption and surface roughness in machining. Journal of Cleaner Production, 83, 151-164. http://dx.doi.org/10.1016/j.jclepro.2014.07.073

Kumar, A., Mahapatra, M. M., Jha, \& P. K. (2014). Effect of machining parameters on cutting force and surface roughness of in situ $\mathrm{Al}-4.5 \% \mathrm{Cu} / \mathrm{TiC}$ metal matrix composites. Measurement, 48, 325-332. http://dx.doi.org/10.1016/j.measurement.2013.11.026

Lalwani, D. I., Mehta, N. K., \& Jain, P. K. (2008). Experimental investigations of cutting parameters influence on cutting forces and surface roughness in finish hard turning of MDN250 steel. Journal of materials processing technology, 206(1), 167-179. http://dx.doi.org/10.1016/j.jmatprotec.2007.12.018

Mahamani, A. (2014). Influence of Process Parameters on Cutting Force and Surface Roughness During Turning of AA2219-TiB2/ZrB2 In-situ Metal Matrix Composites. Procedia Materials Science, 6, 1178-1186.

Marko, H., Simon, K., Tomaz, I., Matej, P., Joze, B., \& Miran, B. (2014). Turning Parameters Optimization Using Particle Swarm Optimization. Procedia Engineering, 69, 670-677. http://dx.doi.org/10.1016/j. proeng.2014.03.041

Nian, C. Y., Yang, W. H., \& Tarng, Y. S. (1999). Optimization of turning operations with multiple performance characteristics. Journal of Materials Processing Technology, 95(1), 90-96. http://dx.doi.org/10.1016/S0924 $-0136(99) 00271-X$

Oktem, H., Erzurumlu, T., \& Kurtaran, H. (2005). Application of response surface methodology in the optimization of cutting conditions for surface roughness. Journal of Materials Processing Technology, 170(1), 11-16. http://dx.doi.org/10.1016/j.jmatprotec.2005.04.096

Rao, C. J., Rao, D. N., \& Srihari, P. (2013). Influence of cutting parameters on cutting force and surface finish in turning operation. Procedia Engineering, 64, 1405-1415. http://dx.doi.org/10.1016/j.proeng.2013.09.222

Shahrom, M. S., Yahya, N. M., \& Yusoff, A. R. (2013). Taguchi method approach on effect of lubrication condition on surface roughness in milling operation. Procedia Engineering, 53, 594-599. http://dx.doi.org/10.1016/j.proeng.2013.02.076 


\section{Appendix}

Table 7. Full isting of experimental samples.

\begin{tabular}{|c|c|c|c|c|c|}
\hline Sample ID & Group & Cutting Speed $(\mathrm{m} / \mathrm{min})$ & Depth of Cut (mm) & Feed Rate (mm/rev) & Surface $\operatorname{Ra}(\mu \mathrm{m})$ \\
\hline 1 & 1 & 75 & 0.1 & 0.025 & 0.602 \\
\hline 2 & & & & 0.050 & 0.202 \\
\hline 3 & & & & 0.100 & 0.827 \\
\hline 4 & & & & 0.150 & 1.616 \\
\hline 5 & & & & 0.200 & 2.924 \\
\hline 6 & 2 & 75 & 0.2 & 0.025 & 0.141 \\
\hline 7 & & & & 0.050 & 0.266 \\
\hline 8 & & & & 0.100 & 0.807 \\
\hline 9 & & & & 0.150 & 1.599 \\
\hline 10 & & & & 0.200 & 3.774 \\
\hline 11 & 3 & 75 & 0.3 & 0.025 & 0.277 \\
\hline 12 & & & & 0.050 & 0.297 \\
\hline 13 & & & & 0.100 & 0.996 \\
\hline 14 & & & & 0.150 & 1.703 \\
\hline 15 & & & & 0.200 & 2.907 \\
\hline 16 & 4 & 75 & 0.4 & 0.025 & 0.232 \\
\hline 17 & & & & 0.050 & 0.252 \\
\hline 18 & & & & 0.100 & 0.88 \\
\hline 19 & & & & 0.150 & 1.996 \\
\hline 20 & & & & 0.200 & 3.068 \\
\hline 21 & 5 & 75 & 0.5 & 0.025 & 0.32 \\
\hline 22 & & & & 0.050 & 0.298 \\
\hline 23 & & & & 0.100 & 0.984 \\
\hline 24 & & & & 0.150 & 1.710 \\
\hline 25 & & & & 0.200 & 2.996 \\
\hline 26 & 6 & 100 & 0.1 & 0.025 & 0.348 \\
\hline 27 & & & & 0.050 & 0.287 \\
\hline 28 & & & & 0.100 & 0.957 \\
\hline 29 & & & & 0.150 & 1.746 \\
\hline 30 & & & & 0.200 & 2.393 \\
\hline 31 & 7 & 100 & 0.2 & 0.025 & 0.228 \\
\hline 32 & & & & 0.050 & 0.314 \\
\hline 33 & & & & 0.100 & 0.771 \\
\hline 34 & & & & 0.150 & 1.622 \\
\hline 35 & & & & 0.200 & 2.789 \\
\hline 36 & 8 & 100 & 0.3 & 0.025 & 0.402 \\
\hline 37 & & & & 0.050 & 0.437 \\
\hline 38 & & & & 0.100 & 0.775 \\
\hline 39 & & & & 0.150 & 1.386 \\
\hline 40 & & & & 0.200 & 3.223 \\
\hline 41 & 9 & 100 & 0.4 & 0.025 & 0.237 \\
\hline 42 & & & & 0.050 & 0.257 \\
\hline 43 & & & & 0.100 & 0.64 \\
\hline 44 & & & & 0.150 & 1.398 \\
\hline
\end{tabular}




\begin{tabular}{|c|c|c|c|c|c|}
\hline 45 & & & & 0.200 & 2.446 \\
\hline 46 & 10 & 100 & 0.5 & 0.025 & 0.147 \\
\hline 47 & & & & 0.050 & 0.247 \\
\hline 48 & & & & 0.100 & 0.753 \\
\hline 49 & & & & 0.150 & 1.500 \\
\hline 50 & & & & 0.200 & 2.31 \\
\hline 51 & 11 & 125 & 0.1 & 0.025 & 0.458 \\
\hline 52 & & & & 0.050 & 0.375 \\
\hline 53 & & & & 0.100 & 0.703 \\
\hline 54 & & & & 0.150 & 1.795 \\
\hline 55 & & & & 0.200 & 3.212 \\
\hline 56 & 12 & 125 & 0.2 & 0.025 & 0.515 \\
\hline 57 & & & & 0.050 & 0.842 \\
\hline 58 & & & & 0.100 & 1.981 \\
\hline 59 & & & & 0.150 & 2.025 \\
\hline 60 & & & & 0.200 & 2.778 \\
\hline 61 & 13 & 125 & 0.3 & 0.025 & 1.063 \\
\hline 62 & & & & 0.050 & 0.588 \\
\hline 63 & & & & 0.100 & 1.575 \\
\hline 64 & & & & 0.150 & 2.054 \\
\hline 65 & & & & 0.200 & 2.65 \\
\hline 66 & 14 & 125 & 0.4 & 0.025 & 0.393 \\
\hline 67 & & & & 0.050 & 0.636 \\
\hline 68 & & & & 0.100 & 1.365 \\
\hline 69 & & & & 0.150 & 1.713 \\
\hline 70 & & & & 0.200 & 2.375 \\
\hline 71 & 15 & 125 & 0.5 & 0.025 & 0.367 \\
\hline 72 & & & & 0.050 & 0.633 \\
\hline 73 & & & & 0.100 & 1.135 \\
\hline 74 & & & & 0.150 & 1.721 \\
\hline 75 & & & & 0.200 & 2.436 \\
\hline 76 & 16 & 150 & 0.1 & 0.025 & 0.470 \\
\hline 77 & & & & 0.050 & 0.563 \\
\hline 78 & & & & 0.100 & 1.068 \\
\hline 79 & & & & 0.150 & 1.675 \\
\hline 80 & & & & 0.200 & 2.502 \\
\hline 81 & 17 & 150 & 0.2 & 0.025 & 0.671 \\
\hline 82 & & & & 0.050 & 0.378 \\
\hline 83 & & & & 0.100 & 0.965 \\
\hline 84 & & & & 0.150 & 1.636 \\
\hline 85 & & & & 0.200 & 2.225 \\
\hline 86 & 18 & 150 & 0.3 & 0.025 & 0.547 \\
\hline 87 & & & & 0.050 & 0.345 \\
\hline 88 & & & & 0.100 & 0.855 \\
\hline 89 & & & & 0.150 & 1.45 \\
\hline 90 & & & & 0.200 & 2.458 \\
\hline 91 & 19 & 150 & 0.4 & 0.025 & 0.495 \\
\hline 92 & & & & 0.050 & 0.269 \\
\hline
\end{tabular}




\begin{tabular}{|c|c|c|c|c|c|}
\hline 93 & & & & 0.100 & 0.866 \\
\hline 94 & & & & 0.150 & 1.715 \\
\hline 95 & & & & 0.200 & 2.317 \\
\hline 96 & 20 & 150 & 0.5 & 0.025 & 0.332 \\
\hline 97 & & & & 0.050 & 0.307 \\
\hline 98 & & & & 0.100 & 0.91 \\
\hline 99 & & & & 0.150 & 1.644 \\
\hline 100 & & & & 0.200 & 2.337 \\
\hline 101 & 21 & 175 & 0.1 & 0.025 & 0.662 \\
\hline 102 & & & & 0.050 & 0.629 \\
\hline 103 & & & & 0.100 & 0.821 \\
\hline 104 & & & & 0.150 & 1.581 \\
\hline 105 & & & & 0.200 & 2.435 \\
\hline 106 & 22 & 175 & 0.2 & 0.025 & 0.832 \\
\hline 107 & & & & 0.050 & 0.365 \\
\hline 108 & & & & 0.100 & 0.857 \\
\hline 109 & & & & 0.150 & 1.670 \\
\hline 110 & & & & 0.200 & 2.649 \\
\hline 111 & 23 & 175 & 0.3 & 0.025 & 0.665 \\
\hline 112 & & & & 0.050 & 0.374 \\
\hline 113 & & & & 0.100 & 0.808 \\
\hline 114 & & & & 0.150 & 1.753 \\
\hline 115 & & & & 0.200 & 2.059 \\
\hline 116 & 24 & 175 & 0.4 & 0.025 & 0.358 \\
\hline 117 & & & & 0.050 & 0.423 \\
\hline 118 & & & & 0.100 & 0.869 \\
\hline 119 & & & & 0.150 & 1.786 \\
\hline 120 & & & & 0.200 & 2.635 \\
\hline 121 & 25 & 175 & 0.5 & 0.025 & 0.441 \\
\hline 122 & & & & 0.050 & 0.477 \\
\hline 123 & & & & 0.100 & 0.745 \\
\hline 124 & & & & 0.150 & 1.92 \\
\hline 125 & & & & 0.200 & 2.487 \\
\hline
\end{tabular}

\section{Copyrights}

Copyright for this article is retained by the author(s), with first publication rights granted to the journal.

This is an open-access article distributed under the terms and conditions of the Creative Commons Attribution license (http://creativecommons.org/licenses/by/3.0/). 